\title{
Lightweight design of direct-drive wind turbine electrical generators: A comparison between steel and composite material structures
}

\author{
Pablo Jaen-Sola ${ }^{1}$, Alasdair S. McDonald ${ }^{1}$, Erkan Oterkus ${ }^{2}$ \\ ${ }^{1}$ Wind Energy Systems Centrefor Doctoral Training, Electronic and Electrical Engineering Department, \\ University of Strathclyde, RoyalCollege Building, 204 George St, Glasgow, G1 1XW, UK \\ ${ }^{2} \mathrm{Naval}$ Architecture and Marine Engineering Department, University of Strathcly de, 100 Montrose St, Glas gow \\ G4 OLZ, UK

\section{pablo.jaen-sola@strath.ac.uk, alasdair.mcdonald@strath.ac.uk, erkan.oterkus@strath.ac.uk}

\begin{abstract}
Direct-drive generators for wind turbines are high torque, low speed machines which require a heavy robust structure to maintain the air-gap clearance open and stable. The mas s of the structural material can be as sessed at the early stages of the design process for radial-flux generators. By using low density materials, such as composites, theentire mas s of the machine can be significantly reduced. A comparison between steel structures and structures made with composite materials working under the same loading conditions is made using small scale $(100 \mathrm{~kW})$ and large scale (3 MW) generator models. Potential improvements to the light weight proposed structures are also suggested.
\end{abstract}

Keywords: Direct-Drive Wind Turbine, Lightweight, Generator Structure, Steel, Composite Materials

\section{Nomenclature}

\section{Roman letters:}

$\begin{array}{ll}E & \text { Young's modulus, } \mathrm{Pa} \\ F & \text { Force caused by the normal component of the Maxwell stress, N } \\ G & \text { Shear modulus, } \mathrm{Pa} \\ g & \text { Acceleration due to gravity, } 9.81 \mathrm{~m} / \mathrm{s}^{2}\end{array}$

\section{Greek letters:}

$\begin{array}{ll}\delta & \text { Distance between fibres, } \mathrm{m} \\ \theta & \text { Cross-sectional area of a single fibre, } \mathrm{m}^{2} \\ v & \text { Poisson's ratio } \\ \rho_{\mathrm{c}} & \text { Composite material density, } \mathrm{kg} / \mathrm{m}^{3}\end{array}$




\section{Introduction}

Wind energy is one of the most developed and mature renewable technologies and has an important role to play in the fight against global warming. Wind resources tend to be greater and steadier offshore and therefore large scale renewable energy projects will be developed further away from shore. For instance, in August 2016, the UK government gave the go-ahead for the world's biggest offshore wind farm off the Yorkshire coast with 300 wind turbines of $7 \mathrm{MW}$ rated power capacity each that will cover an area of more than $480 \mathrm{~km}^{2}$ in the North Sea [1].

In this context, where the offshore wind sector is becoming a key player, a huge effort is being made world wide with the main aim of quickly reducing its high levelized cost and making it capable of competing with conventional electricity production technologies.

Offs hore wind turbines are placed in harsh environments where the wind speeds tend to be higher, the air has high humidity and salt content, foundations and substations are subject to wave and tidal current loading and access can be limited by wave height. Some of the manufacturers' considerations for wind turbine design are low maintenance requirements, easy access to important components, high capacity factors and as sembly with the lightest and cheapest possible crane. Lifting large pieces of equipment offs hore, costs between $£ 10 \mathrm{k}$ and $£ 100 \mathrm{k}$ a day [2]. Thus, lightweight designs are highly desirable.

With large heavy rotating machinery working under tough conditions, minimising the number of moving parts could eventually help diminish the maintenance and mass of the machines. The problems introduced by wind turbine gearboxes could be observed at Scroby Sands, one of the UK's first offshore wind farms. In 2005, 27 intermediate speed and $12 \mathrm{high}$ speed gearbox bearings of the Vestas V-80 wind turbines had to be replaced [3]. In Horns Rev offs hore wind farm Vestas again had to remove and replace 80 of V90 gearboxes [4].

Bearing this in mind, the use of direct-drive generators, where the electrical machine is directly connected to the wind turbine rotor and the gearbox is eliminated, can be a potential solution. Without a gearbox, maintenance downtimes and mass are significantly reduced. Nonetheless, direct-drive generators are quite heavy and robust machines especially designed to withstand large torques and other typical loads present during operation. Therefore, it is also necessary to find a method to minimize its mass. The traditional way is to compare the torque per unit mass between the competing machines. However, these comparis ons are usually based only on the machine active mass, which consists of the copper in the windings, permanent magnets and the rotor and stator back iron. According to Hartkopf $e t$ al. two thirds of the mass of a radial flux electrical machine corresponds to the inactive mass, also known as supporting structure, so this must also be included for an accurate comparison [5]. Significant mass savings leading to machine's substantial cost decrease can be achieved by considering the supporting structure mass during the design stage.

Direct-drive generators are AC synchronous machines that can be permanent magnet or electrically excited. Permanent magnet generators can be considered superior to electrically excited machines because of their lower weight, improved efficiency and compactness. Permanent magnet generators are often characterized by the orientation of the magnetic flux as it travels across the air-gap as

- Radial flux

- Axial flux

- Trans verse flux

Although axial flux and transverse flux machines are of significant interest, this investigation concentrates on radial flux machines. Almost all permanent magnet machines used in large wind turbines are of this topology, typically with an inner rotor of cylindrical shape, with surface-mounted permanent magnets spinning within a stationary armature. Some machines have an outer rotor and inner stator.

The application to wind turbines is unique because of the low speed (in direct-driveturbines) and the requirement for lightweight generators that can be lifted up to and installed on top of high towers.

Electrical and magnetic design and optimization of these radial flux generators is a well understood subject; however the mechanical design is less well characterized. A critical element of the mechanical design is to produce a structure that can maintain the gap between the rotor and the stator open and stable. A good mechanical design would be one that achieves this with a minimum of mass and cost.

When designing electrical machines, the key feature to be considered is a large force acros s the air-gap which is due to the normal component of Maxwell stress (in the order of 200-400 kPa in typical machines). Various 
approaches for minimizing the mass of machine structures dealing with this force and uniform deflection have been proposed [6][7][8][9]. A magneto-mechanical model used for the calculation of the minimum required stiffnes s and mas s of two different types of generators working under a uniform deflection mode was analy tically derived and valid ated in [10]. In [11] and [12], Jaen-Sola and McDonald introduced novel approaches that can be employed to design radial flux machine structures working under distinct deformation modes. As seen, several investigations have been conducted regarding the lightweight design of direct-driveelectrical machines but none of themcontemplated the possibility of changing the current s tructural material (steel) for low density materials.

Lightweight materials, such as composites, have been considered for applications where structures need to comply with demanding requirements at the lowest possible cost and weight, for instance aircrafts, automobiles and ships [13]. In wind turbines, drivetrain weight is highly correlated with machine's capital cost and therefore to its levelized cost too. W ith less weight on top of the tower, the structural requirements for tower and foundations are less demanding. The reduction in mass means a reduction in the cost of material and manufacturing process, as well as time savings. In addition, the combination of an adequate design with the decrease in the amplitude of fatigue loads achieved by the drop in mass contributes to enlarge the wind turbine lifespan. In [14], Shrestha et al. suggested the use of light structural material, such as aluminiumalloy and composites, as a method to reduce the weight of direct-drive machines. In 2012, Siemens patented a wind turbine design where both the rotor and the stator structures are made of composite materials [15].

The main aim of this research is to explore the available options for the design of a composite generator supporting structure and presenta comparis on between typically used steel structures and composite material structures that meet the structural requirements, which means withstanding the loads present during operation and assembly stages of a direct-drive wind turbine permanent magnet generator without deforming more than $10 \%$ of the airgap size [11], in an economic manner. In this paper, a mass comparison between a steel structure, an optimised steel structure, a composite structure modelled by using conventional approaches and a composite structure modelled by using a more advanced methodology is given. The res ults are presented for rotor and stator structures and for large scale ( $3 \mathrm{MW})$ and small scale $(100 \mathrm{~kW})$ models.

\section{Structural Analysis}

This research concentrates on the electrical generator structure. A mas s comparison between ty pical steel structures and composite structures designed using different novel methods is presented. The structural models have been produced and optimis ed making use of finite element techniques and following the stiffness approach introduced by Jaen-Sola and McDonald in [11].

\subsection{Generator Structures}

Different rotor and stator structures were proposed by Stander [16]. Figure 1 illus trates the rotor structures that have been analysed in other papers.
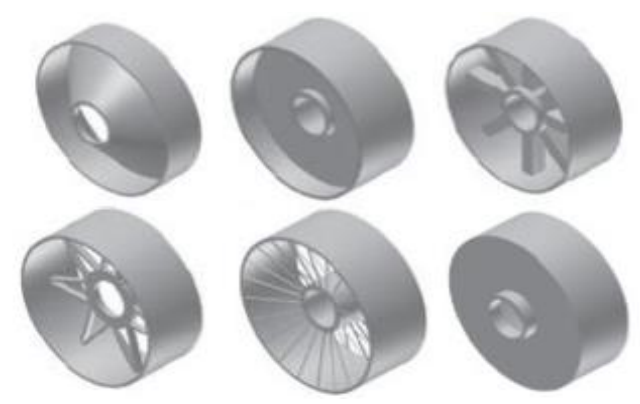

Figure 1 Typical rotor structures [16]

This investigation is centred on structures where discs connect the wind turbine shaft to the rotor surface. As well as connecting the mentioned structures, discs provide the rotor and the stator with the necessary radial and axial stiffnes s to withstand the large loads present during machine's as sembly, transportation and operation stages. Figure 2, dis plays a complete generator structure fully integrated within the turbine and the structural 
models used for evaluation and comparison showing constraints and loading conditions due to magnet attraction forces.

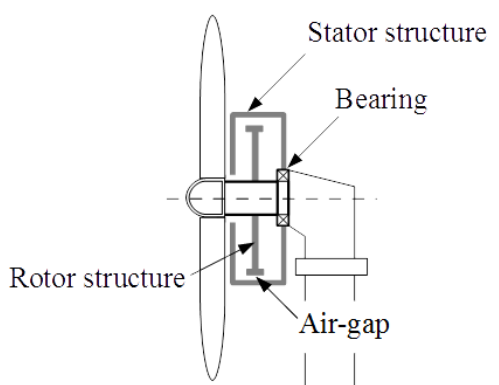

(a)

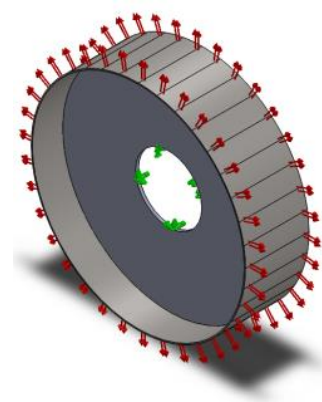

(b)

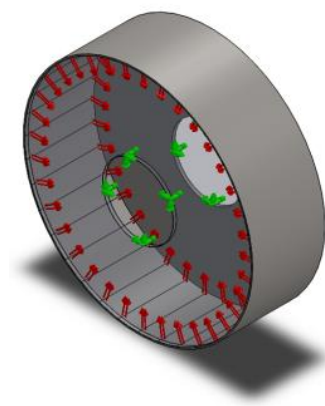

(c)

Figure 2 (a) Generator structure; (b) Rotor structure showing constraints and loading due to magnet attraction forces; (c) Stator structure showing constraints and loading due to magnet attraction forces [10]

Jaen-Sola [17] presented distinct approaches that can be used to es timate the electrical machine structural stiffness and the minimum mas s needed to maintain its integrity. Disc steel structures were analysed and optimised by changing their geometry and by utilizing commercial topology optimization tools (ANSYS). In this paper, a comparison between the structural mass results obtained fromthe said investigation and the outcomes achieved for two composite structures designed following different novel approaches is made in order to demonstrate the potential for further structural performance improvements, as well as mass reduction that the use of lightweight materials, such as composites, can bring to the design.

\subsection{Composite Structure Modelling}

So as to model the supporting composite structure for the electrical machine of a direct-drive wind turbine, a disc structure was selected and a finite element approach was adopted. As proposed for flywheels in [18] and [19] respectively, the ANSYS Parametric Design Language (APDL) was employed to carry out this task as it allows easy parametric changes in material, geometry, mesh, loads and boundary conditions.

The material selected was carbon-epoxy due to its excellent strength-to-weight ratio. When weight, strength and stiffnes s are critical design factors, carbon-epoxy outperforms steel and aluminium. If a weight comparison between these three materials is made per unit volume, it can be obtained that steel is 3 times heavier than aluminium and at the same time, aluminium is 2 times heavier than carbon-epoxy. Table 1 shows the material properties used for this study, 
Table 1 Material properties for a filament wound disc [19]

\begin{tabular}{|c|c|}
\hline$E_{\mathrm{X}}$ & $2.03 \times 10^{11} \mathrm{~Pa}$ \\
\hline$E_{\mathrm{Y}}$ & $1.12 \times 10^{10} \mathrm{~Pa}$ \\
\hline$E_{\mathrm{Z}}$ & $1.12 \times 10^{10} \mathrm{~Pa}$ \\
\hline$v_{\mathrm{XY}}$ & 0.33 \\
\hline$v_{\mathrm{YZ}}$ & 0.45 \\
\hline$v_{\mathrm{XZ}}$ & 0.33 \\
\hline$G_{\mathrm{XY}}$ & $8 \times 10^{9} \mathrm{~Pa}$ \\
\hline$G_{\mathrm{YZ}}$ & $3.8 \times 10^{9} \mathrm{~Pa}$ \\
\hline$G_{\mathrm{XZ}}$ & $4.2 \times 10^{9} \mathrm{~Pa}$ \\
\hline$\rho_{\mathrm{c}}$ & $1,600 \mathrm{~kg} / \mathrm{m}^{3}$ \\
\hline$\delta$ & $5 \times 10^{-6} \mathrm{~m}$ \\
\hline$\theta$ & $1.96 \times 10^{-11} \mathrm{~m}^{2}$ \\
\hline
\end{tabular}

where $E$ corres ponds to the Young's modulus, $G$ is the shear modulus, $v$, is the Pois son's ratio, $\rho_{\mathrm{c}}$ is the density, $\delta$ is the distance between fibres and $\theta$ is the cross-sectional area of a single fibre. Data for the shear modulus in the $\mathrm{YZ}$ and $\mathrm{XZ}$ planes were es timated by using equation (1):

$$
G=\frac{E}{2(1+v)}
$$

Assuming a perfect bonding between fibres and matrix, the distance between fibres, $\delta$, and the cross-sectional area of a single fibre, $\theta$, were chosen so that the highest possible fibre volume fraction can be obtained. The fibre volume fraction, "FVF", utilized to determine the material properties in these analyses is $90 \%$.

The type of element used in the analysis is Shell281. As seen in Figure 3, it owns eight nodes (I, J, K, L, M, N, O and $\mathrm{P}$ ) with six degrees of freedomat each node: translations in the $\mathrm{X}, \mathrm{Y}$ and $\mathrm{Z}$ axes, and rotations about the $\mathrm{X}$, $\mathrm{Y}$ and $\mathrm{Z}$ axes. It is suitable for studying thin to moderately thick shell structures. The element accounts for cons equentialeffects of distributed pressures [20]. Figure 1 dis plays the geometry, node locations and the element coordinate system.

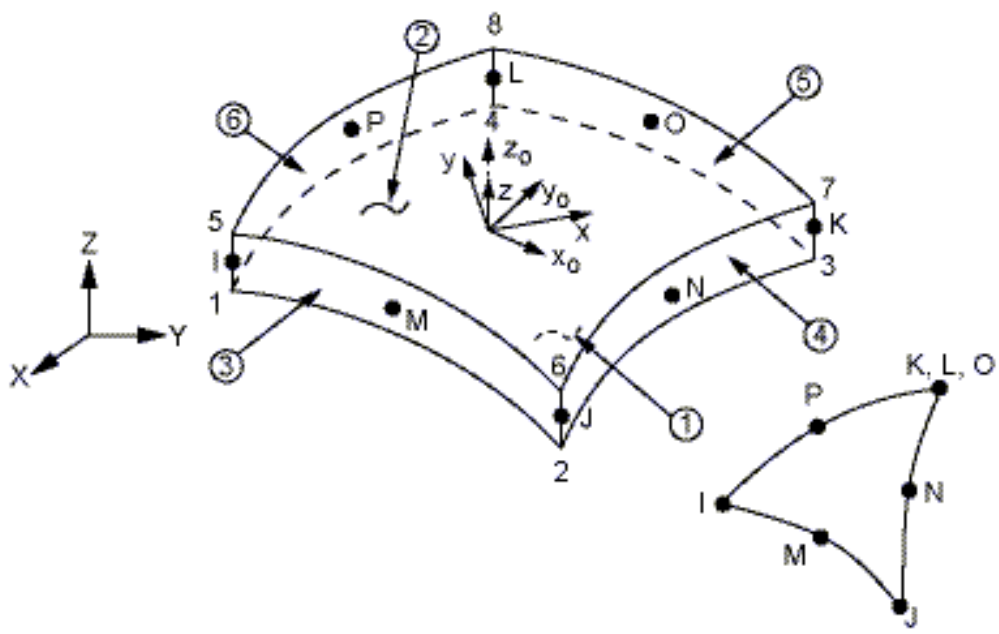

Figure 3 Shell281 Geometry [20] 
The model of the structure was created using the GUI tool available in ANSYS APDL. It was constrained at the shaft and three different types of loads, as described in [17], were applied to the generator structure:

- Radial expansion load in case of the rotor and radial compression load in case of the stator, acting on the rim sub-structure, of $400 \mathrm{kPa}$ corresponding to the Maxwell stress. This corresponds to an air-gap magnetic flux density of $1 \mathrm{~T}$.

- Tangential load again acting on the rim of $30 \mathrm{kPa}$ corresponding to the shear stress. This loading was divided by four and applied in the form of forces of $120 \mathrm{kN}$ for the large scale model and $5.5 \mathrm{kN}$ for the one at a small scale, to the keypoints located at the cylinder midspan and equally spaced. This can be seen in Figure 4.

- Gravitational loading in the Yaxis with $g=9.81 \mathrm{~m} / \mathrm{s}^{2}$. Gravity was als o tes ted in the Z direction in order to consider the weight effect during the generator's transportation stage.

Figure 4 depicts in detail all the loads acting on a generator rotor dis c structure model.

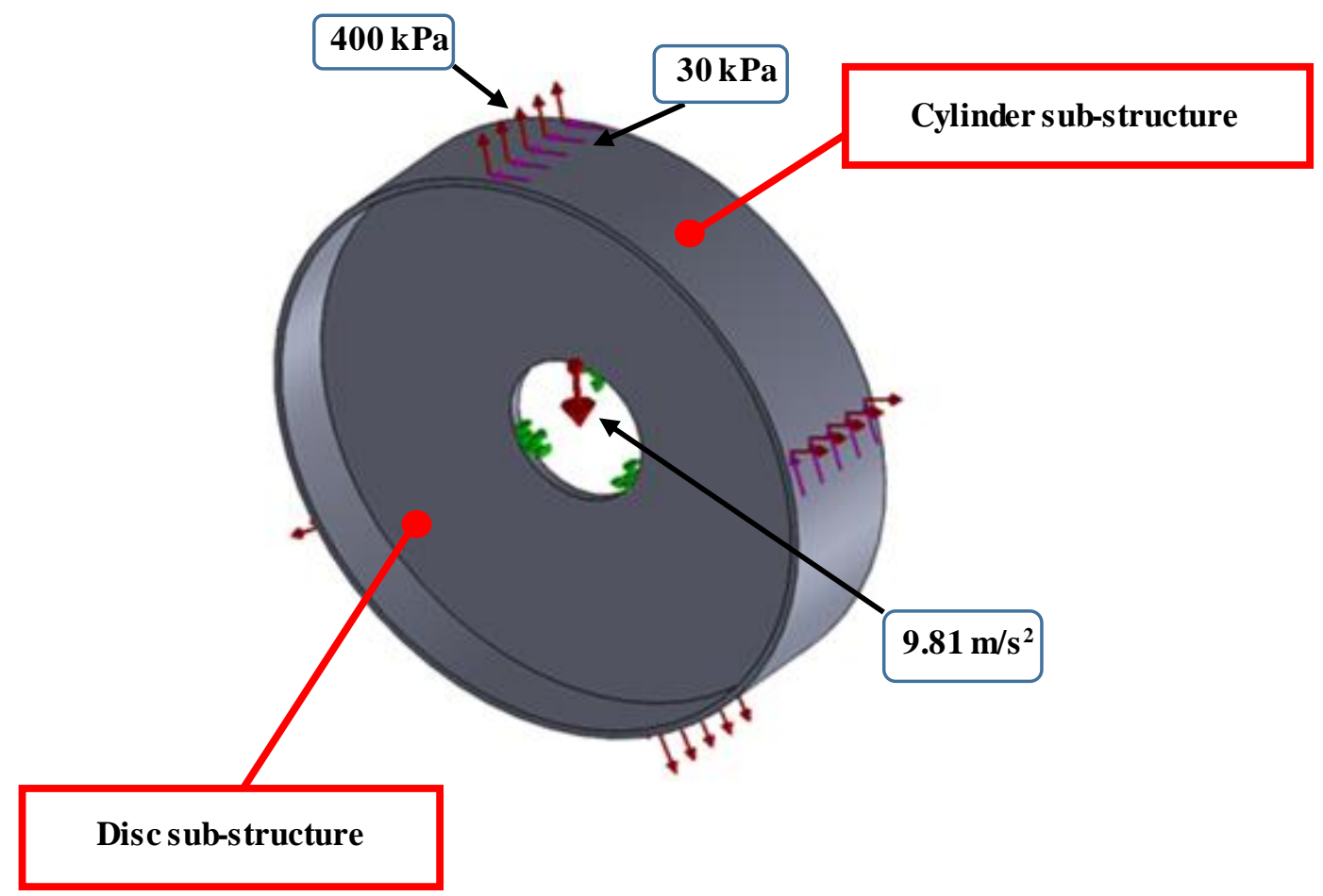

Figure 4 Loads acting on the $3 \mathrm{MW}$ generator rotor structure

As mentioned, two dis tinct methods were used to model the generator composite structure. When creating the model of the disc that is merged with the outer cylinder sub-structure the conventional approach or 'CA' and the mosaic pattern disc approach as stated by Sayem, Morozov and Shankar in [19] were employed.

In the conventional approach ' $\mathrm{CA}$ ', the disc is modelled as a laminated circular plate consisting of a certain number of plies; see Figure 5. The procedure followed to generate this structure is depicted in Figure 6. The mosaic pattem disc is composed by four plies of different thicknesses and orientations depending on the corresponding area. The fibre orientations used when creating the models described above can be seen in detail in Figure 7. For the mo saic pattern model, the disc area is divided into sub-areas as it can be seen in Figure 8.

Electrical machines structures for direct driven wind turbines were modelled at both small and large scales. The benefits of composites are likely to be different at these scales. Therefore, two case studies were performed. At the small scale, a $100 \mathrm{~kW}$ buoy ant airborne wind turbine, als o known as BAT, created by Altaeros Ltd. [21] was investigated. This device shares much of the wind turbine technology with its grounded cousins and also 
introduces additional constraints. One such limitation is the requirement of the turbine equipment to be lightweight. With this in mind, the design of the supporting structure for a generator of $0.42 \mathrm{~m}$ radius and $0.21 \mathrm{~m}$ axial length was started first following the conventional approach to then continue with the more complexo ne. In the early stages, it was thought that fibre reinforcement of certain plies could enhance the stiffness characteristics of the machine modelled using the more complicated configuration. This option was tried, as shown in Figure 9, and discarded as it was observed that it did not introduce any further noticeable improvement to the design. The mesh for the small scale model was created following the same procedure as stated in the following section. However, it is important to highlight that the size for the quads of the inner/outer areas was $0.05 \mathrm{~m}$, whereas for the rest was of $0.005 \mathrm{~m}$. The elements in the areas at the edges had to be refined twice.

Having the s mall scale structure modelled and verified, it was proceeded to draft a $3 \mathrm{MW}$ large scale case study model. The s ame approaches were tracked to design this structure of $2 \mathrm{~m}$ radius and $1.2 \mathrm{~m}$ axial length ag ain with the purpose of minimis ing its mass.

With the composite s tructures finished, a mas s comparison with models made up of steel(AISI304) and designed to comply with the same structural requirements, was carried out. The fulfilment of the structural requirements implied, as already mentioned, that the deflection in all directions must remain below the stipulated limit of $10 \%$ of the air-gap size in the radial direction. For the small scale model that is equal to $0.208 \mathrm{~mm}$, whereas for the large scale it is equal to $0.5 \mathrm{~mm}$.

Two electrical machine supporting structures made with discs have been modelled following the methodology described in this section, one at small scale and one at large scale corresponding to $100 \mathrm{~kW}$ and $3 \mathrm{MW}$ wind turbines, respectively.

So as to come up with a design that can fulfil the structural requirements stated, a factorial design of experiments was developed for both the s mall scale and large scale models. For the models with con ventional configurations a design of experiments process was completed for each section (disc and cylinder). For the mosaic pattem composite structure a design of experiments process was carried out for every area forming the dis c structure and for the cylinder.

After those procedures were completed it was obtained that a s tacking sequence of 90/0/45/0/90 was the one pres enting les s deflection for both the disc and the cylinder of the CA structures regardless of the generat or size. See Table 2 . With this in mind, an optimization process of the thicknesses of the plies was made. It was observed that the influence of the 90 degrees and the 45 degrees plies in the cylinder was negative and elevated the deflection in the sub-structure for both the s mall and the large scale models. Therefore, they were removed. The deflection for each attempted stacking sequence of the laminates forming the CA structure with $5 \mathrm{~mm}$ plies is given in Table 2 .

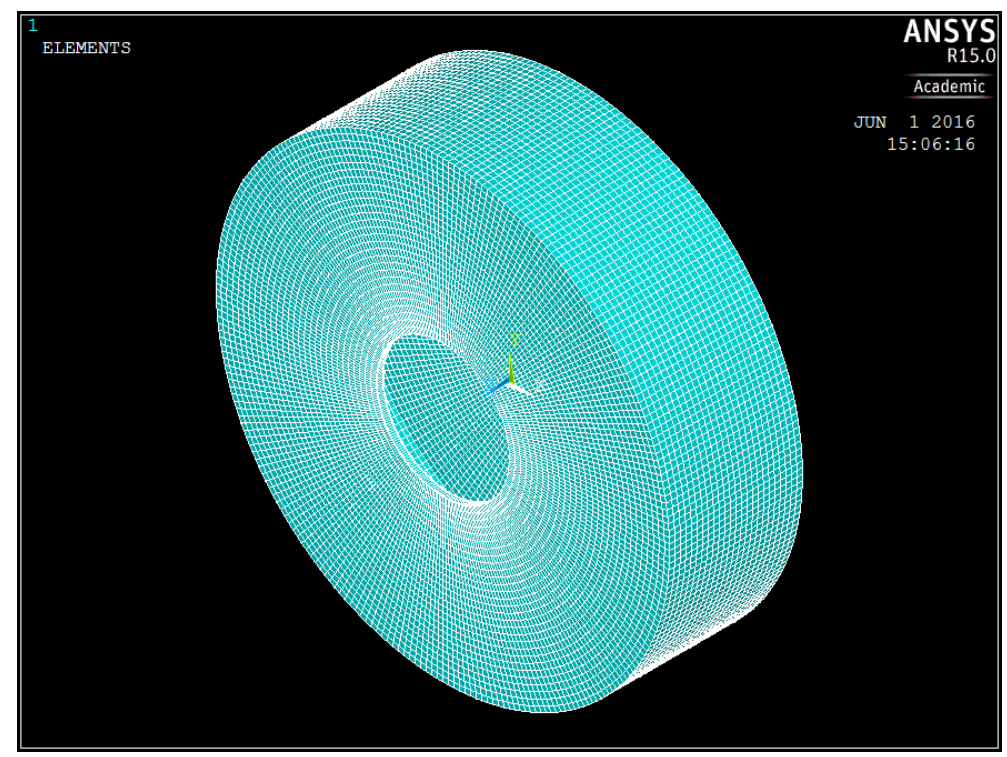

Figure 5 Stator structure according to the conventional method 


\section{Investigation}

\subsection{Conventional Approach}

For this model, the construction of a mesh of an adequate density was determined by an independence study which gave a result of $0.05 \mathrm{~m}$ quad element size. A mapped mesh was used as depicted in Figure 5 for the generator with a 'CA' disc sub-structure. In order to model the inter-laminar properties all the nodes were merged together. This allows the loads to be transferred from one part of the model to another. The orientation of all the fibres within this model was set according to the original Cartesian coordin ate framework and it was as signed to each element through the creation of two different sections, one for the disc sub-structure and one for thecylinder sub-structure. The best stacking sequence for either the disc or the cylinder was found by carrying out a factorial exp erimental design [22]. Three different thicknesses $(0.005 \mathrm{~m}, 0.01 \mathrm{~m}$ and $0.02 \mathrm{~m})$ and three different fibre orientations of 45 , 0 and 90 degrees were as sumed. All the possible combinations for the stacking sequence (keeping symmetry), see Table 2, and thicknesses were tried as stated by the factorial design. For each stacking sequence, the thicknesses of two orientations were fixed to $0.005 \mathrm{~m}$, whereas the one remaining was changed.

After attempting the 54 possible combinations, it was found that 90/0/45/0/90 was the most suitable for the disc and the cylinder sub-structures. The deflection results obtained for the six stacking sequences with all the plies with $0.005 \mathrm{~m}$ thickness are given in Table 2 .

Table 2 'CA' Composite Structure Stacking Sequence

\begin{tabular}{|c|c|c|c|c|c|c|}
\hline $\begin{array}{c}\text { Stacking } \\
\text { Sequence }\end{array}$ & $\begin{array}{c}\text { Outer } \\
\text { Ply (1) }\end{array}$ & $\begin{array}{c}\text { Inner } \\
\text { Ply (1) }\end{array}$ & $\begin{array}{c}\text { Mid } \\
\text { Ply }\end{array}$ & $\begin{array}{c}\text { Inner Ply } \\
(\mathbf{2})\end{array}$ & $\begin{array}{c}\text { Outer } \\
\text { Ply (2) }\end{array}$ & $\begin{array}{c}\text { Deflection(m) for } \\
\mathbf{0 . 0 0 5} \text { m ply thickness }\end{array}$ \\
\hline 1 & 90 & 0 & 45 & 0 & 90 & $1.39 \times 10^{-4}$ \\
\hline 2 & 0 & 90 & 45 & 90 & 0 & $1.4 \times 10^{-4}$ \\
\hline 3 & 45 & 0 & 90 & 0 & 45 & $1.4 \times 10^{-4}$ \\
\hline 4 & 45 & 90 & 0 & 90 & 45 & $1.41 \times 10^{-4}$ \\
\hline 5 & 90 & 45 & 0 & 45 & 90 & $1.4 \times 10^{-4}$ \\
\hline 6 & 0 & 45 & 90 & 45 & 0 & $1.4 \times 10^{-4}$ \\
\hline
\end{tabular}

The last step was to optimize the thicknes s of plies taking into consideration the deflection limit. In the cylinder case, it was observed that the 45 and 90 degree plies did not introduce any improvement in the stiffness of the overall generator structure, hence they were removed, leaving the 0 degrees ply alone, which corresponds to the axial direction. Figure 6 depicts a flowchart describing the process, while in Figure 7 (a)(c), the composite material fibre orientations utilized in this investigation can be recognised. 


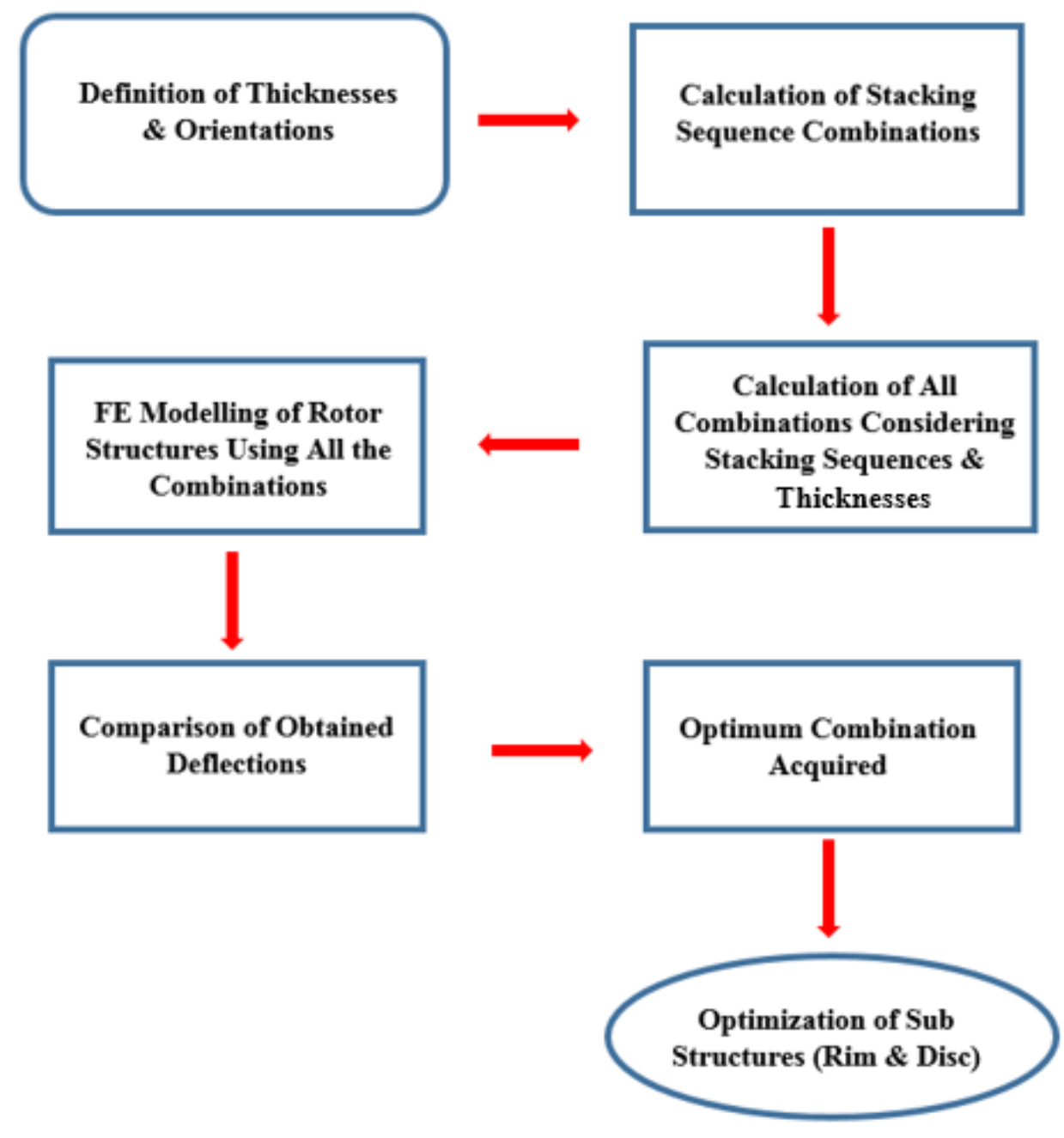

Figure 6 ' $\mathrm{CA}$ ' rotor composite structure design process used in this investigation 


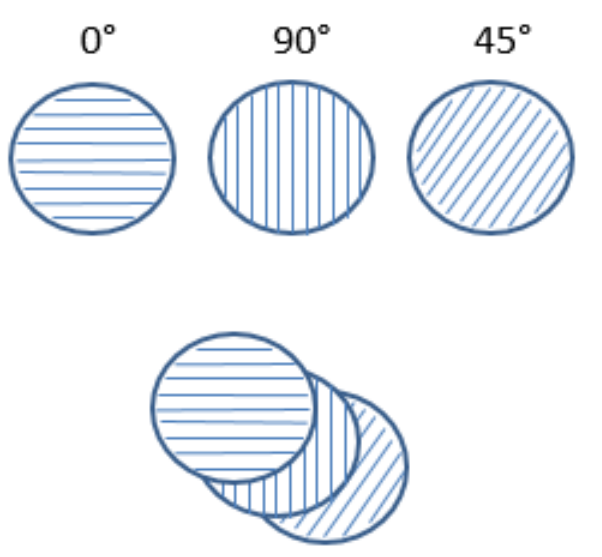

(a)
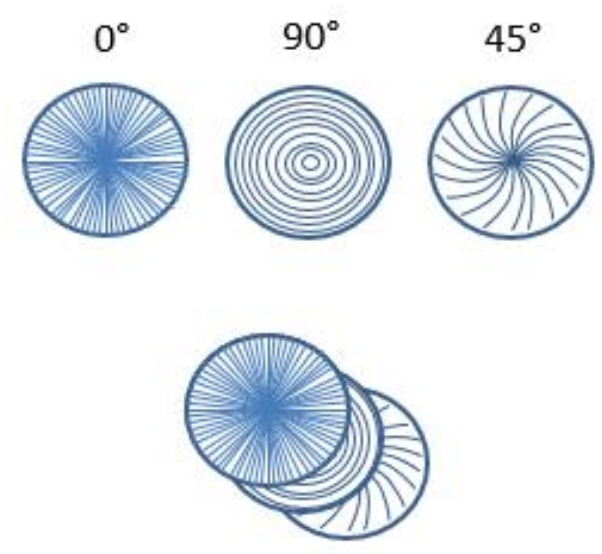

(b)

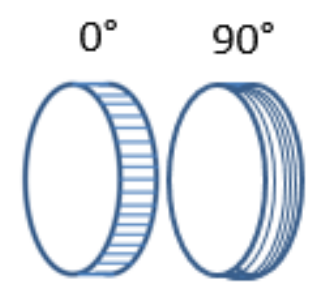

(c)

Figure 7 Example of composite fibre orientations \& stacking sequences for the generators components; (a) Following a Cartesian coordinate frame; (b) Following a cylindrical coordinate frame; (c) For the cylinder sub structure following a cylindrical coordinate s ystem

\subsection{Mosaic Pattern Approach}

For the mos aic pattern disc sub-structure, 5 cy lindrical coordinate systems were created so that the orientation of the fibres in the different areas could be assigned. Eleven unlike sections were generated for the disc, while for the cylinder only one was needed. Afterwards, the sections were applied to the areas. In the first in stance, a quarter of the rotor was developed and then reflected in the X direction with the YZ plane acting as a mirror. Finally, the resultant structure was again mirrored in the $\mathrm{Z}$ axis direction. The same procedure was utilized to model the stator structure. See Figure 8. 


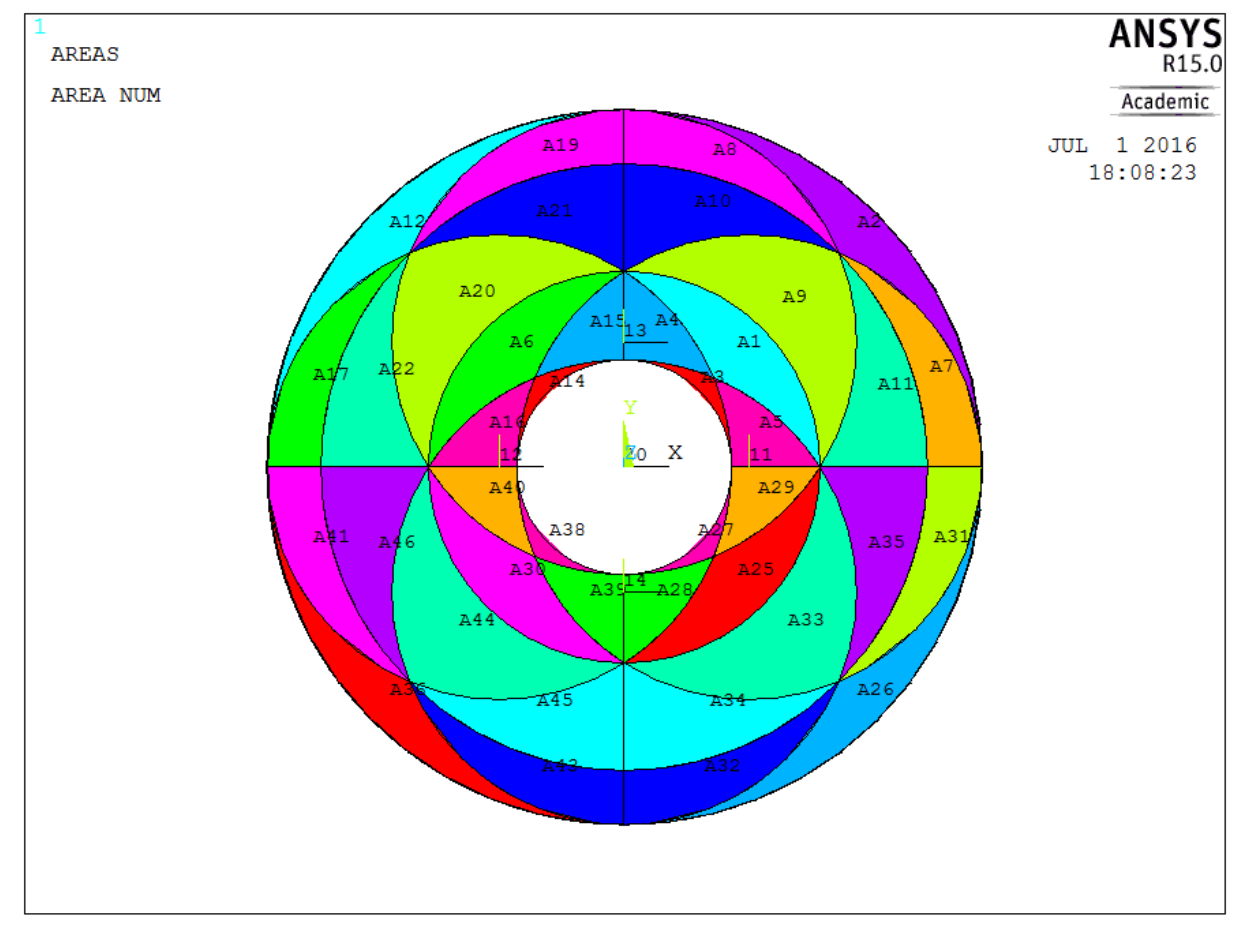

Figure 8 View of the areas forming the mosaic pattern composite disc sub-structure

A more concise mesh control had to be used for this model due to the sharp edges of the outer and inner areas of the disc. As a result, the element size for the mentioned areas was first set to $0.1 \mathrm{~m}$. A free quad mesh was employed, although a triangle one could also be used especially taking into account the shape of these zones obtaining good outcomes. Then, theelements generated were refined twice using the minimal level of refinement available, or level 1, which produces an element of half the length of the original element [20]. The rest of the areas were meshed utilizing a free quad mesh of $0.05 \mathrm{~m}$ element size and no further refinement was necessary. The main aim to use a more refined mesh in the inner/outer zones was to control the shapeand the size of the disc elements merging with the cylinder ones and to avoid errors in the grid creation. See Figure 9.

The models with a more advanced structure, also known as mosaic pattern composite structures, were designed following the guidelines specified above. However, for the first attempt (the small scale model), fibre reinforcement and only one fibre orientation per area as stated by Sayem, Morozov and Shankar in [19] were utilized as observed in Figure 9, where the fibre orientations have been highlighted with coloured arrows matching the colour of the origin of the cylindrical coordinate system that they track. The fibre reinforcement option available in ANSYS APDL allows the user to simulate a cluster of fibres placed according to the structure needs in order to enhance its mechanical properties. Certain key zones were reinforced using smear layers of the same material so that the stiffness of the structure could beimproved. A secure bond between the reinforcing fibres and the base element is assumed by ANSYS and the motion of the reinforcing fibres is determined solely by the motion of the base element as the relative movement between the mentioned components is not allowed [20].

Des pite the potential of this tool no influence in the properties of the structures was noticed. Moreover, the lack of flexibility in the design made extremely difficult to reduce the mass and comply with theimposed specifications at the same time. Thus, this option was discarded. More flexibility was given to the design as requested in search of decent results that would set the path to track. Following the precedent establis hed with the ' $\mathrm{CA}$ ' generator structure, a factorial design of experiments was carried out utilising the same thicknesses and fibre orientations but in this occasion for each area. It was checked that the most suitable fibre orientation for the rim was still 0 degrees and the addition of any ply of any thickness or fibre orientation makes the deflection increase. Once the most favourable orientations were found (for either the dis c areas or the rim), the thicknes ses were optimised so that the overall weight of the structure could be minimized. Thickness of areas with s mall sizes was increased as much as pos sible so the thickness of the largest areas could be decreased. This trade-off process of optimization went on until the deflection limit was reached. 


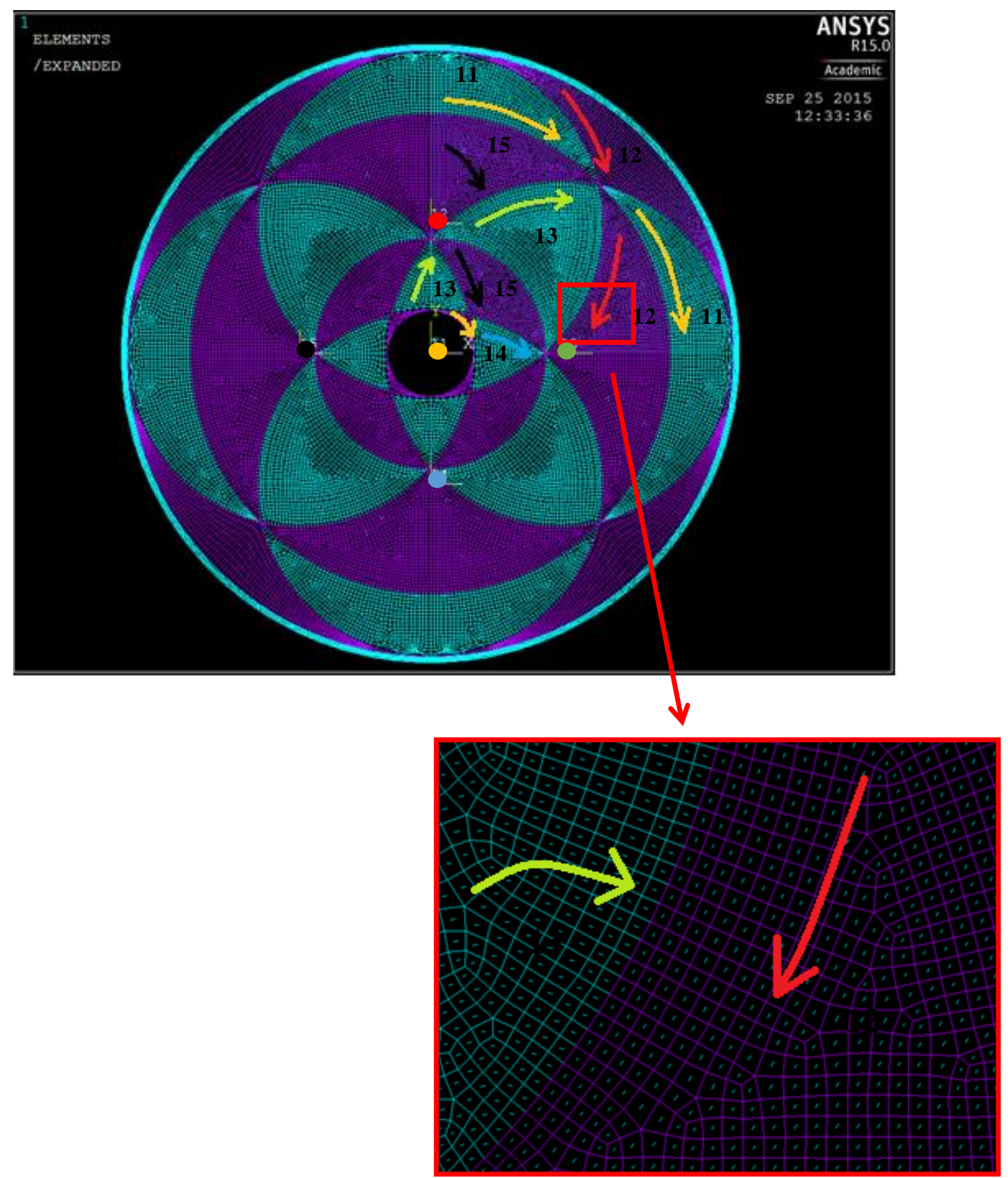

Figure 9 Detailed view of the composite rotor disc structure based on Sayem, Morozov and Shankar's model highlighting variable fibre orientation (small green bits) and reinforcement in purple [23]

\subsection{Conventional Approach vs. Mosaic Pattern Approach}

A comparis on between the Von Mises stress plots for the conventional approach 'CA' and mosaic pattem composite structures is depicted in Figure 10. The Von Mises stress, also known as equivalent tensile stress, is widely used to predict yielding of materials working under complexloading. 


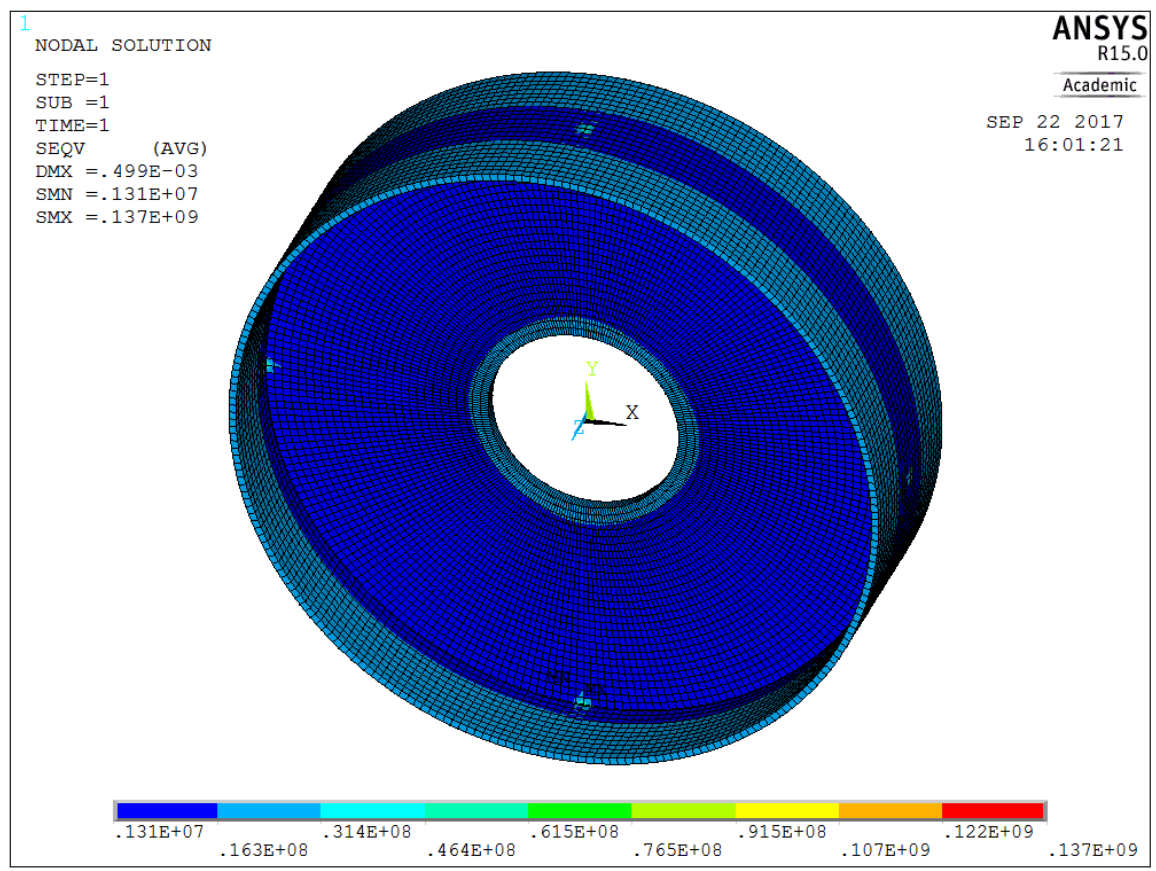

(a)

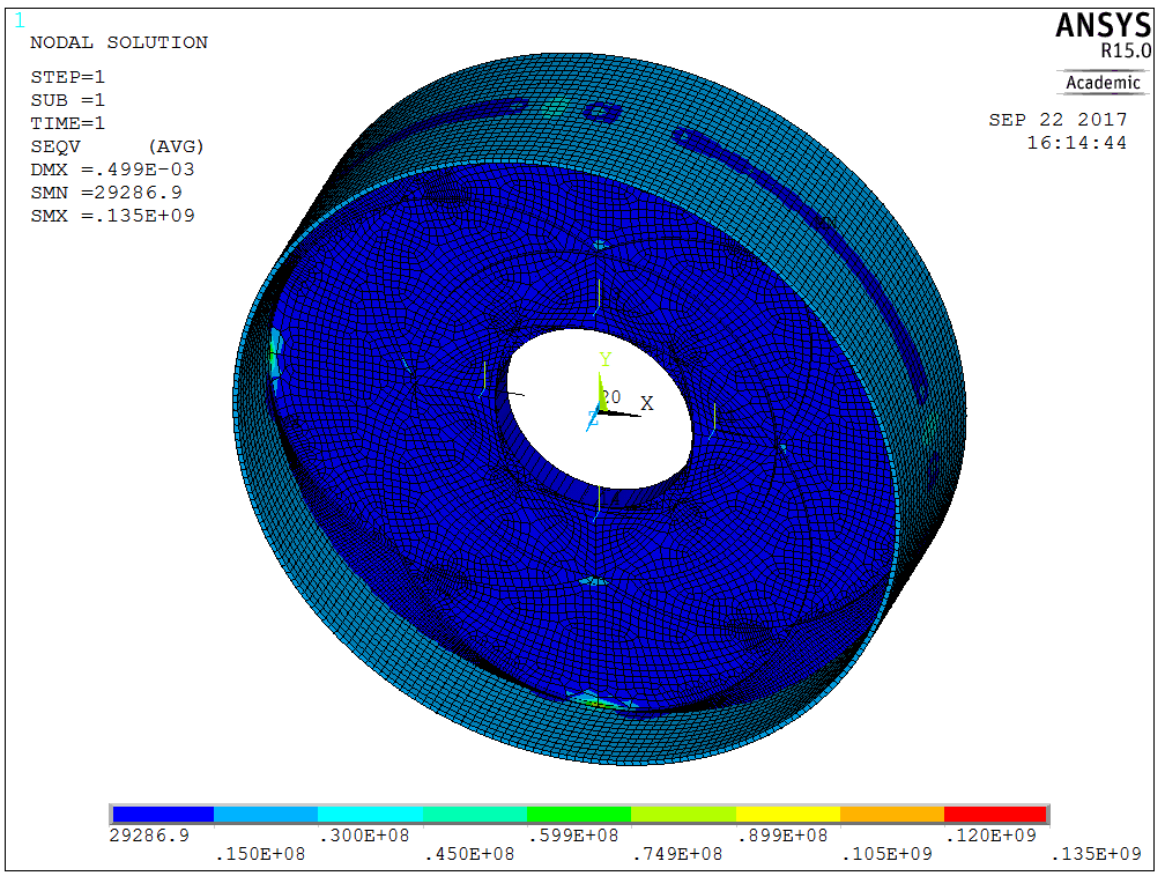

(b)

Figure 10 Contour plots highlighting Von Mises stress (a)CA compositerotor structure (b) Mosaic pattern composite rotor structure

As seen, the rotor composite structure designed using the conventional approach shows an average stress of $0.131 \times 10^{7} \mathrm{~Pa}$ in the whole disc sub-s tructure area, whereas the average value for the mosaic pattern composite disc sub-structure is equal to 29,287 $\mathrm{Pa}$. With this substantial reduction of two orders of magnitude in the disc sub-structure stress, the lifespan of the generator structure can be significantly increased. In addition, the stress concentration that can be observed in the shaft area of the conventional approach structure has been eliminated from the mos aic pattern structure. 
The cylinder sub-structure highlights again a decrease in stress for the mosaic pattern structure of $1.3 \times 10^{6} \mathrm{~Pa}$ if compared with the conventional approach structure. The effect of the fibres interlacing in the mosaic pattern structure aids to spread the stress across both sub-structures, the dis $\mathrm{c}$ and the cylinder, improving the structural performance of the machine and extending the life of the structure.

Table 3 shows the effect of reducing the thickness of the critical areas of the large scale model mosaic pattern disc sub-structure on the deflection. Areas 2 and 3 were not at play as they produced either no noticeable improvement or unacceptable deflections with large stress concentrations.

Table 3 Effect Caused by the Reduction of Critical Areas Thickness

\begin{tabular}{|c|c|c|c|}
\hline Areas & $\begin{array}{c}\text { Thickness Reduction } \\
(\mathbf{m m})\end{array}$ & Mass (kg) & $\begin{array}{c}\text { Total Deflection } \\
(\mathbf{m m})\end{array}$ \\
\hline 1 & 4 & 8 & 0.2 \\
\hline $4 / 5$ & 2 & 4 & 0.1 \\
\hline $8 / 7$ & 2 & 8 & 0.2 \\
\hline 9 & 2 & 8 & $\sim 0.1$ \\
\hline $10 / 11$ & 2 & 9 & 0.4 \\
\hline
\end{tabular}

As understood, the combination of areas 10 and 11, which corres pond to midspan areas of the dis c sub-structure as Figure 8 illustrates, are the ones giving the highest deflection, although they are als o taking away the highest amount of material with $9 \mathrm{~kg}$ per $0.2 \mathrm{~mm}$ of thickness reduction. The combination of areas 4 and 5 gives the lowest deflection but with the lowest mas s reduction, whereas area 1 and the combination of areas 8 and 7 offer fair results with $8 \mathrm{~kg}$ per $0.2 \mathrm{~mm}$ of deflection. The best outcomes were obtained by minimis ing the thickness of area 9 . As seen, $8 \mathrm{~kg}$ of mas s drop was achieved per $0.2 \mathrm{~mm}$ of thickness reduction which gives $\sim 0.1 \mathrm{~mm}$ of deflection.

\section{Results \& Discussion}

Different design approaches for electrical machine supporting structures have been presented in this investigation. Suitable disc steel structures complying with the structural requirements were proposed by Jaen-Sola in [17] for both the small and big scale models. The total mas s (includes rotor and stator structures) of the small scale model made of steel was $313.2 \mathrm{~kg}$ with $114.76 \mathrm{~kg}$ for the rotor and $198.46 \mathrm{~kg}$ for the stator. A further optimization of this structure, using the ANSYS topology optimization tool, was presented showing a total mas s of $266.7 \mathrm{~kg}$, with a mas s of $91.1 \mathrm{~kg}$ for the rotor and $175.6 \mathrm{~kg}$ for the stator. This means a drop of about $15 \%$.

With the lightest steel structure configuration identified for the small scale model, the use of composite materials in the structure design was attempted tracking two distinct methods named conventional approach, 'CA', and mos aic pattern approach. They have been already described in Section 3.

In the case of the 'CA' small structure, the rotor mass was $34.1 \mathrm{~kg}$, while the stator mas s went up to $41.4 \mathrm{~kg}$ giving a total of $75.5 \mathrm{~kg}$. If a comparis on with the optimis ed s teel structure is made, it can be appreciated that a significant reduction of nearly $72 \%$ was achieved.

For the mosaic pattern fibre orientation generator structures, it was estimated that the mas sor the small scale rotor structure is $16.96 \mathrm{~kg}$. The stator structural mass was $33.25 \mathrm{~kg}$. This makes a sumof $50.21 \mathrm{~kg}$, which gives us a difference of about $25.3 \mathrm{~kg}$ with the conventional configuration model. This means an overall reduction in mas s of about $33.5 \%$. The results obtained for the small scale model structures have been plot ted in Figure 11 for comparison. 


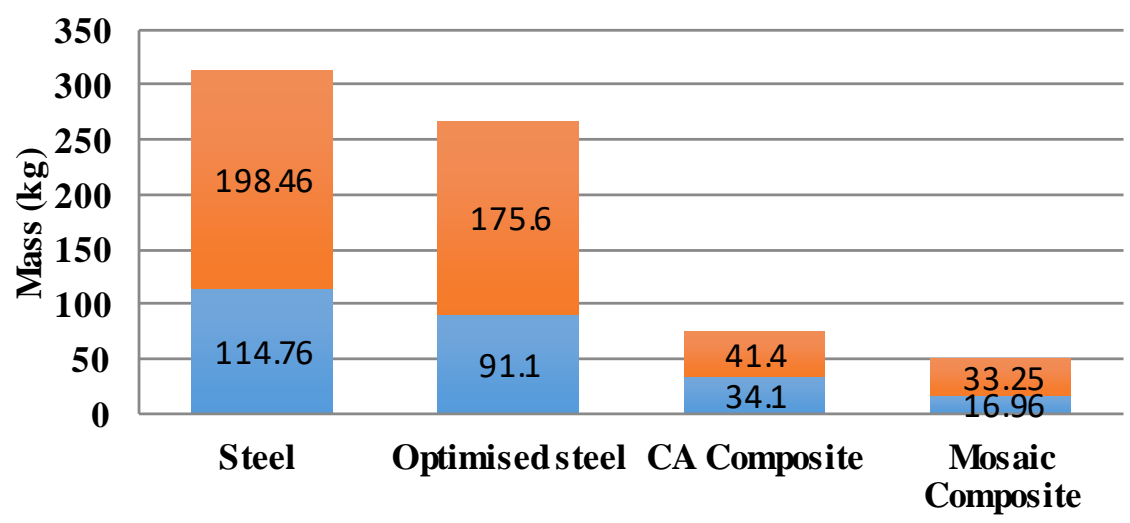

Type of Structure

Rotor Stator

Figure 11 Small Scale Model Corresponding to a $100 \mathrm{~kW}$ Generator (Mass vs. Type of Structure)

Large scale models corresponding to a $3 \mathrm{MW}$ electrical machine supporting structure were developed following the same procedure. In [17], a steel structure was modelled and optimised, achieving a result of 9,809 $\mathrm{kg}$ for the rotor structure and 9,451 kg for the stator. Adding up these values, it was obtained an overall mass of 19,260 kg. After further optimization using the ANSYS Workbench Design Explorer tool [20], Jaen-Sola achieved a mass decrease of $38 \%$. The total mass for the optimised model corresponded to $12,000 \mathrm{~kg}$ with the rotor accounting for $5,694 \mathrm{~kg}$. The mass of the stator structure was $6,306 \mathrm{~kg}$ and as it can be seen, its optimization contributed less to the weight reduction than the rotor one.

Regarding the composite structures, in the case of the 'CA' large scale model, the rotor structure had a mass of $2,488.5 \mathrm{~kg}$, whereas the stator one was of $4,346 \mathrm{~kg}$. The total mass of the generator structure was $6,834.5 \mathrm{~kg}$, which means a drop of $43 \%$ if compared to its optimised counterpart made of steel.

For the mos aic pattern approach large scale model, the rotor had an estimated mass of about $2,418 \mathrm{~kg}$. The mass of the stator structure was about $4,550 \mathrm{~kg}$ giving us an overall value of $6,968 \mathrm{~kg}$. The difference between this model and the one with the conventional layout was $133.5 \mathrm{~kg}$ and it can be neglected. A tiny saving in mass of $70.5 \mathrm{~kg}$ could be made for the rotor, while for the stator a negative result of $204 \mathrm{~kg}$ was understood. Figure 12 shows the outcomes achieved for the large scale structures.

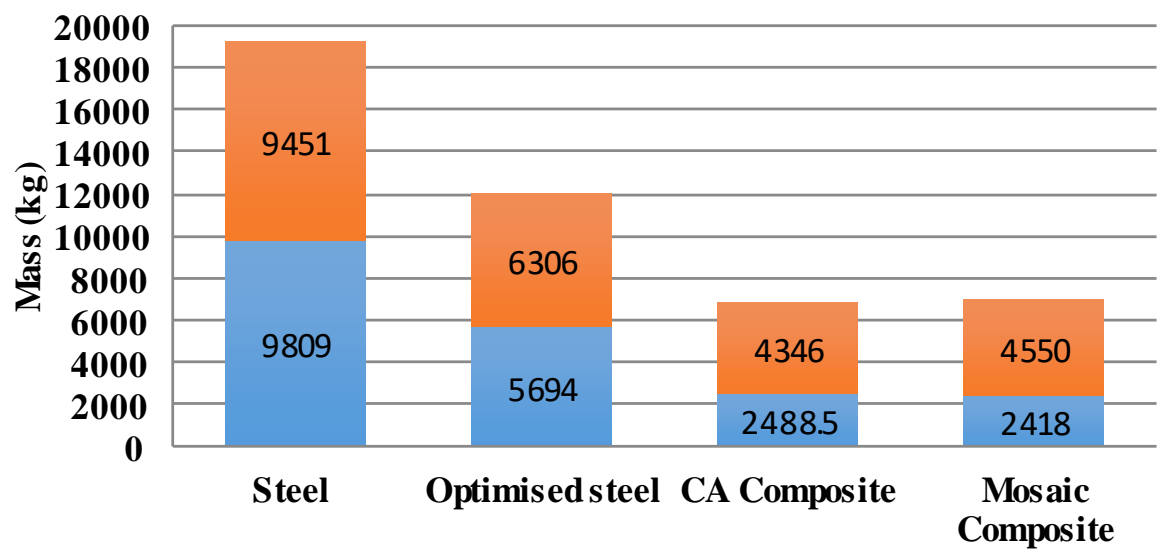

Type of Structure

$\square$ Rotor Stator

Figure 12 Large Scale Model Corresponding to a 3 MW Generator (Mass vs. Type of Structure) 
It could be observed that higher mass savings can be acquired for the rotor structure than for the stator structure. For instance, in the mos aic pattern approach model case, a decrease of almost $50 \%$ was achieved for the rotor, while a $20 \%$ was reached for the stator. This differencecan be explained by looking at the type of loading acting on the structures in question. The rotor structure is subjected to a radial expansion load uniformly distributed along the outer surface of the rim, besides the tangential and gravitational loads. On the contrary, the stator is subjected to a radial load acting on the inner surface of the rim and pointing inwards besides the tang ential and gravity loads. This means that the rotor structure is mainly working under tension when the stator is working under compression. Performance of composites decreases when they work under compression. Typically, mechanical properties of composites working under compression are about $30 \%$ lower than when subjected to tensile stresses. Some of the key mechanical properties of a carbon/epoxy composite rod are shown in Table 4 for reference [24]. Due to this important factor, the thicknesses of the largest areas that form the disc sub-structures of the statorhad to be increased.

Table 4 Carbon/epoxy composite rod $(\mathrm{FVF}=55-60 \%)$ mechanical properties [24]

\begin{tabular}{|c|c|c|c|}
\hline $\begin{array}{c}\text { Tensile strength } \\
\text { longitudinal }(\mathrm{MPa})\end{array}$ & $\begin{array}{c}\text { Compressivestrength } \\
\text { longitudinal }(\mathrm{MPa})\end{array}$ & $\begin{array}{c}\text { Tensile strength } \\
\text { trans verse }(\mathrm{MPa})\end{array}$ & $\begin{array}{c}\text { Compressive stren gth } \\
\text { trans verse }(\mathrm{MPa})\end{array}$ \\
\hline $1100-1900$ & $800-1300$ & 50 & $50-250$ \\
\hline
\end{tabular}

In addition, the configuration of the structures is completely different. This modifies the way the structures withstand the loading. The rim of the rotor is supported by a disc concentrically located and the cylinder of the stator is maintained by two discs placed at its edges. The stator layout introduces further challenges as the main forces are applied to the mid-span area of the rim and larger bending moments and shear forces have to be supported by the discs.

Generally speaking, it can be said that the mos aic pattern model without reinforcements and using multiple fibre orientations gave better results if compared with the conventional model because of the addition of more adaptability to the design. The use of fibre reinforcement and a fixed fibre orientation for each area was seen as a constraint during the early stage of the design as mass optimization could not be carried out if the structural requirements wanted to be fulfilled. For this reas on it was discarded.

By dividing the disc sub-structure area into smaller zones that can have different layups, the designer introduces more variables to play with to this parametric model. The use of several plies with unlike fibre orientations that follow five distinct coordinate systems allows the designer to manage the stress by spreading it or simply concentrating it in purpose into smaller areas. With this, minimization of thickness of large areas can be achieved. Special care has to be taken reg arding the nature of the stress. When designing a structure like this, the avoidance of cyclic loading of large amplitudes is a must. Taking into account the brittle behaviour of this sort of materials, the variable thickness of the structure will play a crucial role in its working life.

The design of the composite structure for the large scale model with a radius of $2 \mathrm{~m}$ and an axial length of $1.2 \mathrm{~m}$ was made following the same procedure as for the small scale one. Very significant mass reductions were acquired for both models, the conventional one and the mosaic pattern one if compared with a structure made of steel. The steel structure optimis ed by Jaen-Sola using the Design Explorer tool of ANSYS Workbench in [17] gave a result for the mass of the whole structure of $12,000 \mathrm{~kg}$. The rotor accounts for 5,694 $\mathrm{kg}$ while the stator weights 6,306 $\mathrm{kg}$. In the worst case scenario, a mass drop of $6,968 \mathrm{~kg}$ could be achieved by utilising composite structures, which means a decrease of nearly $42 \%$. Bearing this mind, it can be said that the use of this type of lightweight materials is a viable option whether a significant structural mass reduction is pursued.

Nevertheless, it is essential to point out that the mosaic pattern design was not able to make any further improvement to the mass reduction due to the design constraints imposed by the low number of areas. Yet, the structural performance of both the rotor and the stator were enhanced as the equivalent tensile stress present in the disc and cylinder sub-structures was significantly reduced.

It is considered that additional mas s reductions could be achieved if the designer goes a step beyond and introduces even more adaptability to the mos aic pattern model. This can be done by considering designs with larger number of areas as proposed in [19], which would help to further decrease the tensile stress enabling bigger thicknesses reduction of the largest areas. Models (a) and (b) displayed in Figure 13 have been analysed in this research, whereas designs (c) and (d) have not been explored. The authors believe that they would introduce the required resilience to approach more ambitiou s optimizations. As suggested in Section 4, the use of more variables would add more complexity to the design. For this, the development of a script that automates the process is recommended. 
Looking at the structural design of the machine from the manufacturing perspective, it can be easily asserted that the more complexity added to the design, the more expensive will be to manufacture the structure. Therefore, the cost of manufacturing, which would include the cost of material, wages of skilled labours, the use of special tooling and handling equipment amongst others, should be estimated before pursuing such investigation. Nevertheless, if the amount of material to be removed is large enough the overall cost could be balanced.

The structural performancehas been enhanced, as it has been demonstrated, by utilising the mosaic pattern model. Working life of the structure is another important input to be included when carrying out the risk analy sis of the potential project.

Last but not least, certain simplifications and as sumptions were made during the accomplis hment of this study. For example, thermal aspects were not considered. The fibres utilized to formcomposite materials have very low coefficients of thermal expansion. Nonetheless, the sensitivity of the composite structure's thermal expansion coefficient to variations fromfibre orientations can be significant as thermal res ponse of the composite materials can be tailored directionally as desired by placing the laminates in the appropriate manner [25]. Due to the complexity and the variety of approaches that could be followed, it was thought that a more concise analysis was required. For this reason, a deep investigation of this field and its effects on the design of any composite structure proposed is recommended.

On the other hand, it was as sumed that steel back iron does not add any strength or stiffness to the structure. By taking into account this feature, more accurate structural optimizations might be achieved.

Finally, this research has no concerns about the connection of any composite s tructure presented here to the shaft, bearing s, turret, bed plate and rotor and stator back iron that can be very challenging. Taking the aircraft industry as an example, titanium fasteners are usually employed to join metallic parts with composites in order to avoid galvanic corrosion. This would add an extra weight that would be necessary to include. In addition, the cost of thes e hardware devices would need to be taken into consideration. 


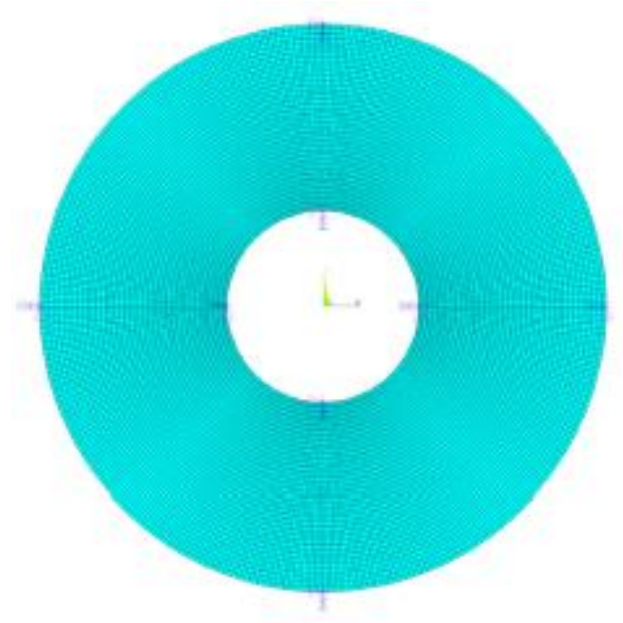

(a)

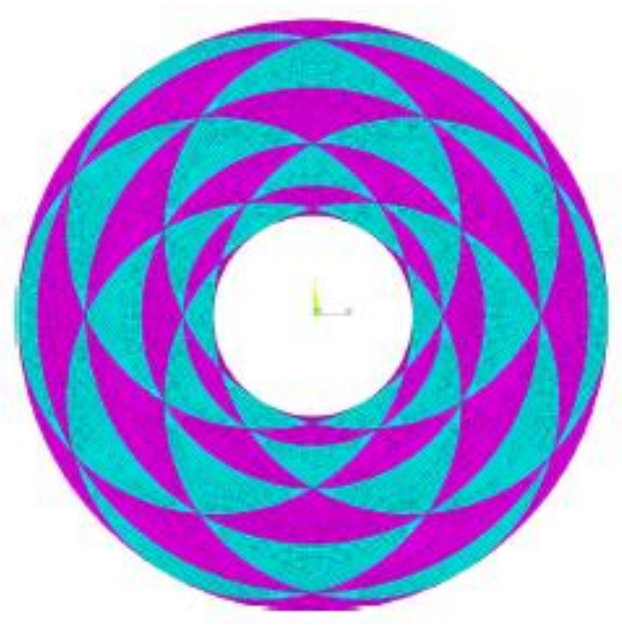

(c)

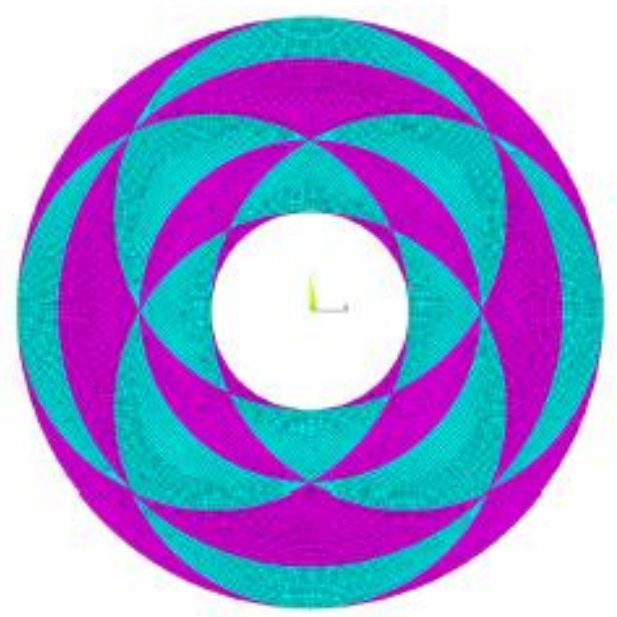

(b)

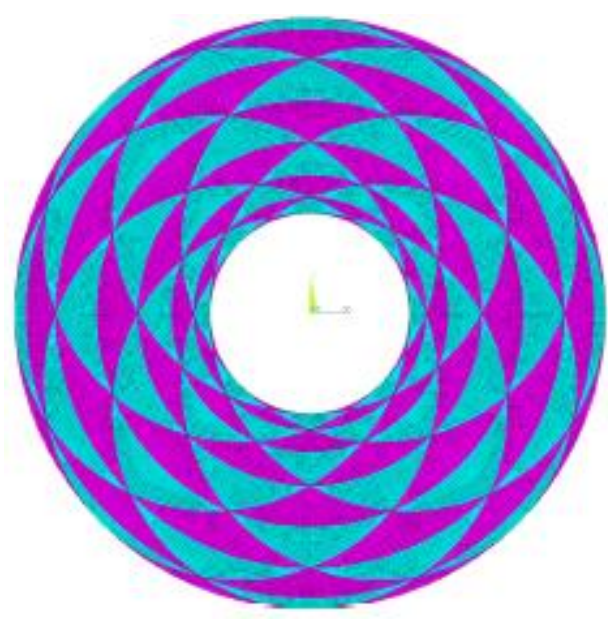

(d)

Figure 13 Potential dis c sub-structure designs (a) Conventional model (b) mosaic pattern approach disc (c) 6unit disc (d) 8-unit disc [19]

\section{Conclusions}

In this research, the possibility of using low density materials in order to minimize the mass of the overall generator structure has been explored. Two different approaches have been utilized: a conventional method and a more advanced approach, which divided the full area of the disc sub-structure into smaller zones. Both techniques were employed to optimize the mass of the rotor and the stator of two models one at a small scale and another at a large scale. A comparis on between the small scale model created following the conventional approach and an optimised steel structure under the same loads and constraints showed that the composite structure was $72 \%$ lighter than the steel one.

Afterwards, an evaluation of the mass of the ' $\mathrm{CA}$ ' structure and the structure modelled tracking the mo saic pattem approach revealed a difference of $33.5 \%$ in favour of the mosaic pattern design, as well as a better structural performance. The mas s of this model was also contrasted with the one of a model made of steel working under the same circumstances, giving a mass drop of about $82 \%$.

A similar procedure was followed for the large scale model. The mas ses of the models designed following the conventional and the mosaic pattern approaches were contrasted with their optimised counterpart made of steel revealing a drop in mass of about $60 \%$. Later on, the masses and performances of the two composite structures 
were compared. No significant difference in mass was observed, although the more advanced mosaic pattem model showed a better structural performance. Further improvements might be acquired if more adaptability is added to the design.

Looking at the results obtained, it can be concluded that the use of materials with higher Young's Modulus to density ratios, such as composites, is without doubt, an option to betaken into consideration when attempting the design of lightweight electrical generator structures or any other type of weight sensitive rotating piece of machinery working in a similar environment.

\section{Acknowledgments}

We would like to thank Professor David Infield and Dr Ozan Keysan from the Electronic and Electrical Engineering departments of the University of Strathclyde, in Glasgow (UK), and the Middle East Technical University, in Ankara (Turkey), respectively, for providing valuable feedback on this article.

\section{References}

[1] The guardian, https://www.theguardian.com/environment/2016/aug/16/hornsea-project-two-windfarmsecond-phase-grims by. Last accessed [Online] 16/11/2016.

[2] A.S. McDonald, "Structural analysis of low speed, high torque electrical generators for direct drive renewable energy converters", Ph.D. dis sertation, University of Edinburgh, Edinburgh, 2008.

[3] E. de Vries, 'Trouble spots - Gearbox failures and design solutions', Renewable Energy World, Mar. 2006, 9, (2), pp.37-47.

[4] J. Wallace, M. Jacks on, S. Rogers, “The problemwith O\&M”, Renewable Energy Focus Journal, Volume 9, No. 7, pp. 22-7, January-February 2009.

[5] T. Hartkopf, M. Hofmann, S. Jöckel, 'Direct-drive generators for megawatt wind turbines'. European Wind Energy Conf., Dublin, Ireland, 1997, pp. 668-671.

[6] A. S. McDonald, M. Mueller and H. Polinder, "Structural mass in direct drive permanent magnet electrical generator," IET Renewable Power Generation Special Is sue-Selected Papers fromEWEC 2007, vol.2, no. 1, pp. 3-15, March 2008.

[7] M. A. Mueller, A. S. McDonald, "A lightweight low-speed permanent magnet electrical generator for direct-drive wind turbines," Wiley Wind Energy, vol. 12, Issue 8, pp. 768-780, Nov. 2009.

[8] A.Zavvos, A. S. McDonald, M. A. Mueller, "Optimis ation tools for large permanent magnet generators for direct drive wind turbines", IET Renewable Power Generation Journal, vol. 7, Issue 2, pp. 163-171, Nov. 2012.

[9] A.Zavvos, A. S. McDonald, M. A. Mueller, "Electromagnetic and Mechanical Optimisation ofDirectDrive Generators for Large W ind Turbines," $5^{\text {th }}$ IET International Conference on Power Electronics, Machines and Drives (PEMD2010), Apr. 2010.

[10] A. S. McDonald, P. Jaen-Sola, "A New Method forCoupling Structural and Magnetic Models for the Design and Optimization of Radial Flux PM Generators for Direct-Drive Renewable Energy Applications", IET Renewable Power Generation Journal, submitted Oct. 2017.

[11] P. Jaen-Sola, A. S. McDonald, "Structural Analy sis and Characterization of Radial Flux PM Generators for Direct-Drive Wind Turbines", $3 r d$ Renewable Power Generation Intermational Conference (RPG 2014), Naples (Italy), Sept. 2014.

[12] P. Jaen-Sola, A. S. McDonald, "A Comparative Study of Methods forModelling the Structural Stiffnes s ofGenerator Components", $8^{\text {th }}$ IET International Conference on Power Electronics, Machines \& Drives (PEMD 2016), Glasgow (UK), Apr. 2016. 
[13] American Composites Manufacturers Association, "Where are composites used?", www.acmanet.org/composite/where-are-composites-used, 2016. Last Accessed [Online] 05/05/2016.

[14] G. Shrestha, H. Polinder, D. Bang, and J. A. Ferreira, "StructuralFlexibility : A Solution for Weight Reduction of Large Direct-Drive," in IEEE Transactions on Energy Conversion, 2010, vol. 25, no. 3, pp. 732-740.

[15] H. Lind, S. O. Stiesdal, “Wind Turbine,” Patent, WO 2013/083386 A2, 2013.

[16] J. N. Stander, G. Venter, and M. J. Kamper, "Review of direct-drive radialflux wind turbine generator mechanicaldesign,"W iley Wind Energy Journal, vol. 15, Issue 3, pp. 459-472, Apr. 2012.

[17] P. Jaen-Sola, "Advanced Structural Modelling and Design of Wind Turbine Electrical Generators", Ph.D. thes is, Wind Energy Systems CDT, Univers ity of Strathcly de, Glas gow, UK, Sept. 2017.

[18] A. Abdul-aziz, G. Baaklini, and J. Trudell, "Structural Analysis of Composite Flywheels : An Integrated NDE and FEM Approach,” NASA, John H. Glenn Res earch Center, Cleveland, Ohio , Jan. 2001.

[19] M. Sayem, E. V. Morozov and K. Shankar, "The effect of filament winding mosaic pattern on the stress state of filament wound composite flywheel disk," Composite Structures, vol. 107, pp. 260-275, Jan. 2014.

[20] ANSYS Apdl, Help topics. ANSYS, 2015.

[21] Altaeros Energies, “www.altaerosenergies.com/,”2014. Last Accessed [Online] 01/09/2016.

[22] The Pennsylvania State University, "https://methodology.psu.edu/ra/most/factorial," Introduction to Factorial Experimental Design, 2016. Last Accessed [Online] 01/09/2016.

[23] P. Jaen-Sola, A. S. Mcdonald, and E. Oterkus, "A Lightweight Approach for Airborne Wind Turbine Drivetrains," in European Wind Energy Association International Conference, Paris (France), Nov. 2015, pp. 1-9.

[24] Carbon/epoxy compositerod material information - Goodfellow, "www.goodfellow.com/A/CarbonEpoxy-Composite.html,"2019. Last Accessed [Online] 11/02/2019.

[25] R. R. Johnson, M. H. Kural, and G. B. Mackey, “Thermal Expansion Properties of Composite Materials", Lockhead Mis siles and Space Company, Inc., NASA Contractor Report 165632, Sunnyvale, California, 1981. 